\title{
EFEITO DA CELULASE SOBRE A DECOMPOSIÇÃO DO PERGAMINHO E SUA INFLUÊNCIA NA VELOCIDADE E PORCENTAGEM DE GERMINAÇÃO DE SEMENTES DE CAFEEIRO ${ }^{1}$
}

\author{
Effect of the cellulase about the decomposition of the parchment and speed \\ of germination of coffee seeds
}

\author{
Juliana de Fátima Sales ${ }^{2}$, Amauri Alves de Alvarenga ${ }^{3}$, João Almir de Oliveira ${ }^{4}$, Francisco Dias Nogueira ${ }^{5}$, \\ Fabiano Guimarães Silva ${ }^{6}$, André Dely Veiga ${ }^{7}$
}

\begin{abstract}
RESUMO
Com este trabalho, objetivou-se verificar a ação da celulase sobre a decomposição do pergaminho das sementes de cafeeiro. Foram implantados dois experimentos, sendo o primeiro, realizado em condições in vitro. Constituído por três ensaios para avaliar os efeitos das concentrações da enzima, do substrato e sacarificação enzimática do pergaminho. O segundo, foi realizado em condições in vivo, com imersão das sementes de cafeeiro em solução de celulase na concentração de 1,6 g.L $\mathrm{L}^{-1}$ em tampão citrato de potássio 0,05 mol. $L^{-1}$. Observou-se que a quantidade de açúcar liberado in vitro foi diretamente relacionada com a concentração de enzima, e que houve aumento expressivo e linear na quantidade de açúcares redutores liberados nas duas concentrações $\left(1,6\right.$ e 3,2 g.L. $\left.L^{-1}\right)$ à medida que se aumentou o tempo de incubação das amostras de substrato (pergaminho) com a solução enzimática. Foi verificado também, nos testes de germinação e emergência, que as sementes sem pergaminho apresentam maiores índices de velocidade e porcentagem de germinação e emergência comparado às sementes com pergaminho e que a celulase nesta concentração ainda não proporciona aumento na velocidade de germinação das sementes, necessitando-se de concentrações mais elevadas.
\end{abstract}

Termos para indexação: Coffea arabica L., enzima, tempo de imersão.

\begin{abstract}
This paper aimed to verify the action of cellulase on the decomposition of parchment of coffee seeds. For this purpose two experiments were conducted and the first, was realized in vitro conditions, containing of three assays (effect of the concentration of the enzyme, effect of the concentration of the substrate and enzyme scarification of the parchment). The second was made in vitro conditions soaking of coffee seeds in a cellulase solution at the concentration of 1.6 g.L $\mathrm{L}^{-1}$ in $0.05 \mathrm{M}$ potassium citrate buffer. It was found that the amount of sugar released was directly related with the enzyme concentration and that there was a linear and marked increase in the amount of reducing sugars released at the concentrations (1.6 and $\left.3.2 \mathrm{~g} . \mathrm{L}^{-1}\right)$ well as incubation time of the substrate samples (parchment) with the increase of enzyme solution. It was also found that the parchmentless seeds presented increase in the germination and emergence velocity index, germination and emergence percentage as compared with the seeds with a parchment and that cellulase at this concentration do not provide any increase in germination velocity of seeds, being needed higher concentrations.
\end{abstract}

Index terms: Coffea arabica L.; enzyme, soaking time.

\section{(Recebido para publicação em 13 de janeiro de 2004 e aprovado em 7 de julho de 2005)}

\section{INTRODUÇãO}

Além da difícil conservação durante o armazenamento, as sementes de café germinam de maneira lenta e desuniforme, trazendo transtornos aos produtores de mudas em muitas regiões, principalmente em Minas Gerais, Estado de grande expressão na cultura do cafeeiro, cuja época de semeadura, na maioria das vezes, coincide com o período de temperaturas mais baixas, retardando o desenvolvimento das mudas.

A região sul do Estado de Minas Gerais, segundo Nechet (1999), destaca-se como sendo a maior produtora de café do País, contribuindo com cerca de $34 \%$ da produção nacional. Anualmente, a participação relativa média do café no valor total das exportações brasileiras, incluindo os produtos básicos e os produtos industrializados, é de aproximadamente 5\% (ANUÁRIO..., 1997).

\footnotetext{
${ }^{1}$ Parte do trabalho de dissertação da primeira autora para obtenção do título de Mestre em Agronomia/Fisiologia Vegetal.

2 Bióloga, M.Sc., Professora Adjunta do Departamento de Biologia da Universidade de Rio Verde/ FESURV - Rio verde, GO - Doutoranda em Agronomia/Fitotecnia (UFLA) - jfsales@fesurv.br

${ }^{3}$ Doutor, Professor Titular do Departamento de Biologia - Universidade Federal de Lavras/UFLA - Cx. P. 3037 - $37.200-000$ - Lavras, MG

${ }^{4}$ Doutor, Professor Adjunto do Departamento de Agricultura, UFLA.

${ }^{5}$ Doutor, Pesquisador - UFLA/EPAMIG.

${ }^{6}$ Doutor, Professor do Centro Federal de Educação Tecnológica de Rio Verde.

${ }^{7}$ Engenheiro Agrônomo, Doutorando em Agronomia/Fitotecnia - Universidade Federal de Lavras/UFLA - Cx. P. 3037 - 37.200-000 Lavras, MG.
} 
Diante deste fato, torna-se fundamentalmente importante o desenvolvimento de técnicas que permitam a germinação mais rápida e uniforme das sementes, o que levará a ganhos significativos no tempo de obtenção das mudas e seu estabelecimento mais rápido no campo, menor índice de replanta, além de permitir maior uniformidade no desenvolvimento da lavoura e um retorno mais rápido dos investimentos.

A difícil digestão do pergaminho é devida à sua constituição que contém celulose, que é um componente básico da parede celular e um dos compostos mais abundantes na natureza. É um composto constituído de resíduos de glicose unidos por ligações glicosídicas do tipo b-1,4. Na maioria das vezes, ela se encontra associada com outros polissacarídeos como hemicelulose, pectina e lignina, dificultando sua degradação (MARCONDES et al., 1983).

A hidrólise da celulose pode ser realizada por meio de tratamentos ácidos ou básicos e, ainda, por ação de enzimas celulolíticas produzidas pela flora microbiana, como pelos fungos Trichoderma viride, Trichoderma reesei (MARCONDES et al., 1983), por Aspergilus sp, pela bactéria ruminal celulolítica Clostridium cellobioparum e, ainda possivelmente, por outros tipos de organismos como térmitas (cupins) (HOWARD \& ELLIOTTI, 1988).

De acordo com Howard \& Elliotti (1988), tratamentos de sementes de Euonymus americanus com fluido ruminal contendo Clostridium cellobioparum tiveram sua germinação aumentada substancialmente, pelo fato deste microrganismo sintetizar endocelulase, o que favoreceu a embebição e, conseqüentemente, a germinação das sementes.

Com este trabalho objetivou-se estudar atividades in vitro da enzima celulase sobre a decomposição do endocarpo das sementes, visando aumentar a velocidade de germinação e conseqüentemente reduzir o período de formação de mudas de cafeeiro.

\section{MATERIAL E MÉTODOS}

Foram realizados dois experimentos com a finalidade de se conhecer as atividades in vitro e in vivo: o primeiro foi composto por três ensaios, sendo utilizados pergaminhos retirados manualmente de sementes da cultivar Acaiá do Cerrado, colhidas na Estação Experimental da EPAMIG, no município de Lavras, MG, no ano de 2001. Estes foram macerados em nitrogênio líquido e para a avaliação da atividade enzimática foi utilizada metodologia de Howard \& Elliott (1988).
Para avaliar o efeito da concentração da enzima celulase sobre a velocidade de degradação, foram testadas nove concentrações de celulase de Aspergillus niger, (SIGMA): 0,0; 0,1; 0,2; 0,4; 0,8; 1,6; 3,2; 6,4 e 12,8 gramas da enzima por litro da solução tampão citrato de potássio 0,05 mol. $\mathrm{L}^{-1}, \mathrm{pH} 4,8$. Em seguida, foram retiradas alíquotas de $100 \mathrm{~mL}$ da solução enzimática e colocadas em tubos de ensaio contendo $6 \mathrm{mg}$ de pergaminho. Na sequiência, colocou-se a mistura em banho-maria a $50^{\circ} \mathrm{C}$ por 30 minutos. Posteriormente, adicionou-se $1 \mathrm{~mL}$ de solução de ácido 3,5 dinitrossalicílico (DNS). Por fim, foi adicionado $1,4 \mathrm{~mL}$ de água destilada e, as leituras espectrofotométricas em número de quatro repetições por tratamento, realizadas imediatamente a $540 \mathrm{~nm}$ para a quantificação de açúcares redutores.

O efeito da concentração de substrato (pergaminho) sobre a atividade da enzima celulase foi realizado através de alíquotas de $100 \mathrm{~mL}$ da solução da enzima celulase $(1,6$ $\mathrm{g}$ de enzima por litro de tampão citrato 0,05 mol.L $\mathrm{L}^{-1}$ a pH 4,8, quantidade esta estabelecida por testes preliminares) e adicionadas em tubos de ensaio contendo 10, 20, 40 e 80 $\mathrm{mg}$ do macerado de pergaminho. A seguir, colocou-se a mistura em banho-maria a $50^{\circ} \mathrm{C}$ por 30 minutos. Posteriormente, acrescentou-se $1 \mathrm{~mL}$ de solução de ácido 3,5 dinitrossalicílico (DNS). Acrescentou-se 1,4 $\mathrm{mL}$ de água destilada e em seguida, procederam leituras a $540 \mathrm{~nm}$, em número de quatro repetições por tratamento, para a determinação de açúcares redutores presentes no meio de reação.

Na sacarificação enzimática do pergaminho, foram tomadas $6 \mathrm{mg}$ do substrato pergaminho em tubos de ensaio e acrescentadas alíquotas de $100 \mathrm{~mL}$ de soluções enzimáticas (1,6 e 3,2 g.L.-1 $)$, preparadas em tampão citrato de potássio 0,05 mol. $\mathrm{L}^{-1}$, $\mathrm{pH} 4,8$ e incubadas em banhomaria à temperatura de $50^{\circ} \mathrm{C}$ por diferentes intervalos de tempo $(0 ; 0,5 ; 1 ; 2 ; 3 ; 4 ; 5 ; 6 ; 7 ; 8 ; 9$; e 10 horas $)$. Acrescentou-se $1 \mathrm{~mL}$ de DNS. Foi adicionado $1,4 \mathrm{~mL}$ de água destilada sendo a atividade celulásica determinada espectrofotometricamente a $540 \mathrm{~nm}$ pelo método do DNS, em quatro repetições por tratamento, para a quantificação de açúcares redutores.

No segundoexperimento, sementes de cafeeiro com e sem pergaminho, da cultivar Acaiá do Cerrado, foram imersas em diferentes tempos e soluções de celulase com o objetivo de se diminuir o tempo de germinação das sementes. Em seguida, as sementes foram submetidas aos testes de germinação e vigor. $\mathrm{O}$ teste de germinação conduzido com 4 repetições de 50 sementes foi feito em 
rolos de papel "germitest" umedecidos com água destilada na quantidade de 2,5 vezes o peso do papel e mantidas em câmaras de germinação, sob luz constante e temperatura de $30^{\circ} \mathrm{C}$. Foi calculado, além da porcentagem de germinação (plântulas normais), o IVG (Índice de Velocidade de Germinação). Para isto fez-se contagens diárias, computando-se o número de sementes que apresentavam início de protrusão da radícula (plântulas normais) para a determinação do IVG, que foi calculado segundo a fórmula de Maguirre (1962). A porcentagem de germinação foi obtida após 60 dias de semeadura, computando-se o número de plântulas normais, segundo as Regras para Análise de Sementes (BRASIL, 1992).

Para a determinação do Índice de Velocidade de Emergência e da porcentagem de emergência, as sementes em quatro repetições de 50 sementes, foram semeadas em bandejas plásticas, contendo uma mistura de terra e areia em proporções iguais. Foram feitas contagens diárias do número de plântulas emergidas, sendo consideradas emergidas plântulas com os cotilédones e o endosperma emersos do solo (estádio de muda ou seedling, fase "palito"). O IVE foi calculado da mesma forma que o IVG, de acordo com a fórmula de Maguirre (1962) e a porcentagem de emergência (plântulas normais) após completa estabilização do estande, aos 80 dias de semeadura.

Tanto na determinação do IVG quanto IVE, o delineamento experimental foi em blocos casualisados, no esquema fatorial com quatro repetições de 50 sementes, compreendendo-se os seguintes tratamentos: dois tipos de sementes (com e sem pergaminho), três substâncias de imersão [celulase de Aspergillus niger (1,6 g. $\mathrm{L}^{-1} \mathrm{em}$ tampão citrato de potássio 0,05 mol.:-1 $, \mathrm{pH} 4,8$ ), tampão citrato de potássio e somente em água destilada] e cinco tempos ( 0 , 24, 48, 72 e 144 horas de imersão).

\section{RESULTADOS E DISCUSSÃO}

Pela Figura 1a observa-se que a quantidade de açúcar liberado foi diretamente relacionada com a concentração de enzima, sendo que em concentrações mais elevadas, aumentou-se de maneira acentuada a quantidade de açúcares redutores produzidos. Estes resultados estão de acordo com Howard \& Elliott (1988). Os autores trabalharam com sementes de Euonymus americanus e verificaram que a quantidade de açúcar redutor liberado de sementes estava diretamente relacionada com concentração de enzima da solução enzimática.

Verificou-se que na concentração de substrato de $20 \mathrm{mg}$, houve maior atividade da enzima (Figura 1b). Na concentração de 46,62 mg de substrato, houve um decréscimo acentuado, provavelmente devido a uma inibição parcial da enzima e na concentração de $80 \mathrm{mg}$ houve tendência de estabilização, devido à saturação dos sítios ativos.

Verifica-se pela Figura 2, que houve aumento expressivo e linear na quantidade de açúcares redutores liberados nas duas concentrações $\left(1,6\right.$ e 3,2 g.L $\left.\mathrm{L}^{-1}\right)$ à medida que se aumentou o tempo de incubação das amostras de substrato (pergaminho) na presença da solução enzimática (Figura 2). Nota-se também que houve maior atividade enzimática quando se utilizou a maior concentração, no caso, 3,2 g.L. $\mathrm{L}^{-1}$. Howard \& Elliott (1988) constataram que houve aumento na quantidade de açúcares redutores com o aumento do tempo de contato entre sementes e extratos enzimáticos.
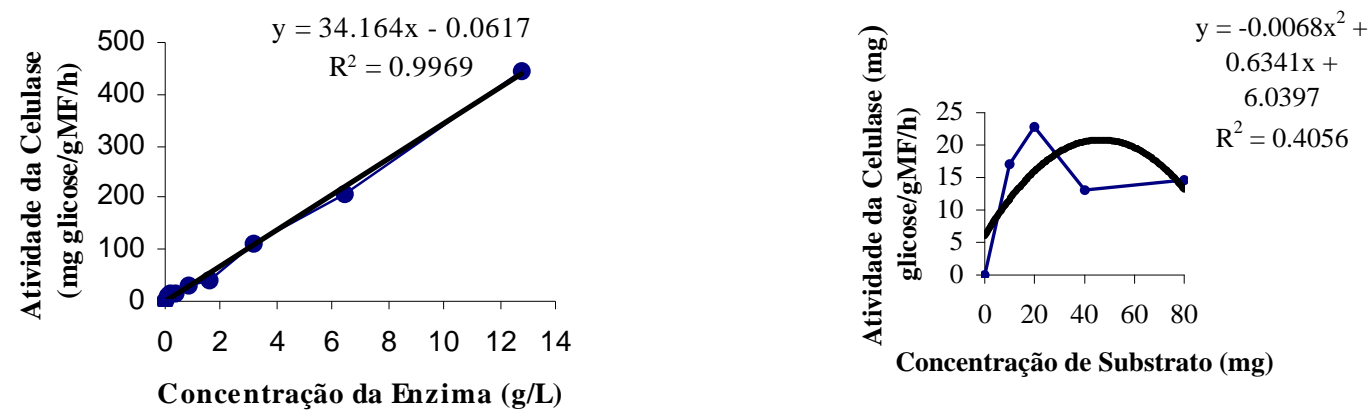

FIGURA 1 - Efeito da concentração de enzima sobre a velocidade da reação (a) e da quantidade do substrato sobre a velocidade da reação (b), em pergaminho de sementes de cafeeiro.

Ciênc. agrotec., Lavras, v. 29, n. 6, p. 1146-1152, nov./dez., 2005 


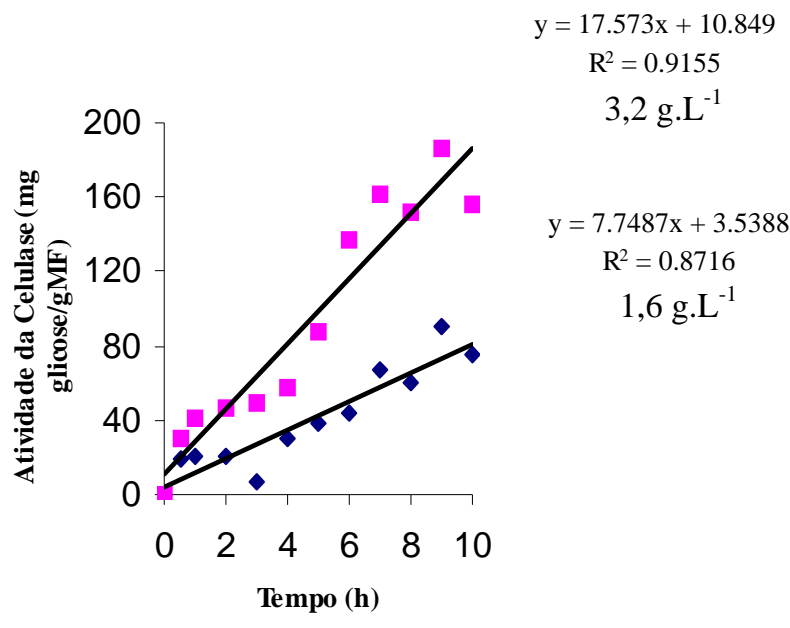

FIGURA 2 - Sacarificação enzimática do pergaminho de sementes de cafeeiro em solução de celulase em concentrações de 1,6 g.L $\mathrm{L}^{-1}$ e 3,2 g.L.-

Foi verificado que em sementes com pergaminho imersas em celulase no tempo de 72 horas houve maior IVG do que naquelas imersas em água e tampão (Tabela 1). No tempo de 144 horas, as sementes imersas em água apresentaram maior IVG, embora não tenha diferido daquelas imersas em água, mas foi estatisticamente superior às imersas em solução tampão. Guimarães (2000) constatou que sementes de cafeeiro imersas em água por 8 dias a $30^{\circ} \mathrm{C}$ proporcionou aumentos nas taxas de germinação. Neste mesmo sentido, Camargo (1998) verificou que o IVG aumentou de 1,34 no tratamento controle para 2,72 em sementes imersas em água por 9 dias.

Verifica-se que sementes sem endocarpo apresentaram IVG superior às sementes com endocarpo em todas as soluções de imersão analisadas (Tabela 1). Estes resultados confirmam os obtidos por França (1970), Guimarães (1995) e Rena \& Maestri (1986), que verificaram que a retirada manual do endocarpo da semente é uma prática que contribui para acelerar a germinação de sementes de cafeeiro. Segundo Lima (1999), sementes de cafeeiro com endocarpo absorvem menor quantidade de água em relação às sementes sem endocarpo. O maior IVG ocorreu em sementes imersas por 144 horas, independente da solução utilizada, evidenciando que a imersão por um período mais longo faz com que as sementes passem pelas fases iniciais da germinação mais rapidamente que as não imersas, ocorrendo a protrusão da radícula mais rápida. De uma maneira geral, foi verificado um aumento partindo da ausência de imersão (0 hora) até 144 horas nas três soluções avaliadas.

TABELA 1 - Índice de velocidade de germinação (IVG) em sementes de cafeeiro após a imersão por diferentes períodos em solução de celulase (1,6 g.L-1 $)$, tampão citrato de potássio 0,05 M e água.

\begin{tabular}{cccccccc}
\hline \multirow{2}{*}{ TS $^{\mathbf{X}}$} & \multirow{7}{*}{ Solução } & \multicolumn{7}{c}{ Tempo de imersão (h) } \\
\cline { 3 - 8 } & \multicolumn{1}{c}{$\mathbf{0}$} & $\mathbf{2 4}$ & $\mathbf{4 8}$ & $\mathbf{7 2}$ & $\mathbf{1 4 4}$ & Média \\
\hline \multirow{4}{*}{$\mathrm{CE}$} & Celulase & $0,13 \mathrm{Aa}^{\mathrm{Y}}$ & $0,05 \mathrm{Aa}$ & $0,17 \mathrm{Aa}$ & $0,34 \mathrm{Aa}$ & $0,24 \mathrm{Aab}$ & $0,19 \mathrm{a}$ \\
& Tampão & $0,10 \mathrm{Aa}$ & $0,09 \mathrm{Ab}$ & $0,05 \mathrm{Aa}$ & $0,05 \mathrm{Ab}$ & $0,10 \mathrm{Ab}$ & $0,07 \mathrm{a}$ \\
& Água & $0,07 \mathrm{Ba}$ & $0,04 \mathrm{Bb}$ & $0,06 \mathrm{Ba}$ & $0,09 \mathrm{Bab}$ & $0,43 \mathrm{Aa}$ & $0,14 \mathrm{a}$ \\
& Média & $0,10 \mathrm{AB}(\mathrm{b})$ & $0,06 \mathrm{~B}(\mathrm{~b})$ & $0,09 \mathrm{AB}(\mathrm{b})$ & $0,16 \mathrm{AB}(\mathrm{b})$ & $0,26 \mathrm{~A}(\mathrm{~b})$ & $0,13(\mathrm{~b})$ \\
& Celulase & $4,61 \mathrm{Ca}$ & $5,18 \mathrm{Ba}$ & $5,38 \mathrm{Bab}$ & $5,39 \mathrm{Bb}$ & $6,11 \mathrm{Ab}$ & $5,33 \mathrm{~b}$ \\
$\mathrm{SE}$ & Tampão & $4,63 \mathrm{Da}$ & $4,89 \mathrm{CDb}$ & $5,19 \mathrm{Cb}$ & $5,74 \mathrm{Ba}$ & $6,45 \mathrm{Aa}$ & $5,38 \mathrm{~b}$ \\
& Água & $4,81 \mathrm{Ca}$ & $4,99 \mathrm{Cab}$ & $5,52 \mathrm{Ba}$ & $5,79 \mathrm{Ba}$ & $6,68 \mathrm{Aa}$ & $5,56 \mathrm{a}$ \\
& Média & $4,68 \mathrm{E}(\mathrm{a})$ & $5,02 \mathrm{D}(\mathrm{a})$ & $5,36 \mathrm{C}(\mathrm{a})$ & $5,64 \mathrm{~B}(\mathrm{a})$ & $6,41 \mathrm{~A}(\mathrm{a})$ & $5,42(\mathrm{a})$ \\
\hline
\end{tabular}

${ }^{\mathrm{x}}$ Tipo de semente (CE, com endocarpo; SE, sem endocarpo). ${ }^{\mathrm{Y}}$ Médias seguidas pela mesma letra maiúscula na horizontal e minúscula na vertical dentro de cada tipo de semente, não diferem entre si pelo teste de Tukey ao nível de $5 \%$ de probabilidade. Letras entre parênteses deverão ser comparadas apenas entre tipos de sementes dentro de cada tempo de imersão. 
Observa-se que sementes com endocarpo apresentaram porcentagem de germinação inferior às sementes sem endocarpo (Tabela 2), em razão da barreira natural exercida pelo endocarpo que dificulta a entrada de água, refletindo também na velocidade de germinação das sementes de cafeeiro. Sementes com endocarpo imersas em celulase por 48 e 144 horas e em água por 144 horas, apresentaram porcentagens de germinação superiores. Em sementes sem endocarpo não foram verificadas diferenças entre os tempos de imersão e soluções de imersão.

Em sementes com endocarpo (Figura 3), não houve efeito significativo da solução de imersão sobre o IVE, em cada tempo de imersão analisado, o que não foi observado para sementes sem endocarpo, em que as imersas em água no tempo de 24 horas de imersão apresentaram em média, maior IVE, seguido do tampão e por último celulase.

O IVE foi maior em sementes sem o pergaminho (Figura 4). Como verificado neste tipo de sementes, as que foram imersas em água se destacaram, apresentando melhores índices de emergência em 24 horas de imersão e o maior IVE das sementes sem endocarpo foi obtido quando estas foram imersas em água por 24 horas, e os demais tempos não diferiram entre si.

Analisando o efeito do tempo de imersão sobre o tipo de solução em sementes com endocarpo foi verificado que o tempo exerceu influência significativa sobre a emergência das plântulas (Tabela 3). Para sementes sem endocarpo, apenas aquelas imersas 144 horas em celulase diferiram estatisticamente dos demais, apresentando menor porcentagem de emergência.

TABELA 2 - Porcentagem de germinação de sementes de cafeeiro após imersão por diferentes períodos em solução de celulase $\left(1,6\right.$ g. $\left.\mathrm{L}^{-1}\right)$, tampão citrato de potássio $0,05 \mathrm{M}$ e água.

\begin{tabular}{|c|c|c|c|c|c|c|c|}
\hline \multirow{2}{*}{$\mathrm{TS}^{\mathrm{x}}$} & \multirow{2}{*}{ Solução } & \multicolumn{6}{|c|}{ Tempo de imersão (h) } \\
\hline & & 0 & 24 & 48 & 72 & 144 & Média \\
\hline \multirow{4}{*}{$\mathrm{CE}$} & Celulase & $9,5 \mathrm{Ba}^{\mathrm{Y}}$ & $3,5 \mathrm{Ba}$ & $18,5 \mathrm{Aa}$ & $7 \mathrm{Ba}$ & $18 \mathrm{Ab}$ & $11,30 \mathrm{a}$ \\
\hline & Tampão & $8 \mathrm{Aa}$ & $7 \mathrm{Aa}$ & 4,5 Ab & 3,5 Аа & $6,5 \mathrm{Ac}$ & $5,90 \mathrm{~b}$ \\
\hline & Água & $6 \mathrm{Ba}$ & $4 \mathrm{Ba}$ & $6 \mathrm{Bb}$ & $8,5 \mathrm{Ba}$ & 33,5 Аa & 11,60 a \\
\hline & Média & $7,83 \mathrm{BC}(\mathrm{b})$ & 4,83 B(b) & 9,66 B(b) & 6,33 BC(b) & $19,33 \mathrm{~A}(\mathrm{~b})$ & 9,6 (b) \\
\hline \multirow{4}{*}{$\mathrm{SE}$} & Celulase & $97,0 \mathrm{Aa}$ & 98,5 Аа & 98,5 Аа & 96,0 Аа & $97,5 \mathrm{Aa}$ & 97,5 a \\
\hline & Tampão & $97,0 \mathrm{Aa}$ & 97,0 Аа & 97,0 Аа & $98 \mathrm{Aa}$ & $99 \mathrm{Aa}$ & $97,6 \mathrm{a}$ \\
\hline & Água & $96,5 \mathrm{Aa}$ & 98,0 Аа & 99,5 Аа & 99,5 Аа & 98,5 Аа & 98,4 a \\
\hline & Média & $96,83 \mathrm{~A}(\mathrm{a})$ & $97,83 \mathrm{~A}(\mathrm{a})$ & $98,33 \mathrm{~A}(\mathrm{a})$ & $97,83 \mathrm{~A}(\mathrm{a})$ & $98,33 \mathrm{~A}(\mathrm{a})$ & $97,83(a)$ \\
\hline
\end{tabular}

${ }^{\mathrm{x}}$ Tipo de semente (CE, com endocarpo; SE, sem endocarpo). ${ }^{\mathrm{Y}}$ Médias seguidas pela mesma letra maiúscula na horizontal e minúscula na vertical dentro de cada tipo de semente, não diferem entre si pelo teste de Tukey ao nível de $5 \%$ de probabilidade. Letras entre parênteses deverão ser comparadas apenas entre tipos de sementes dentro de cada tempo de imersão.

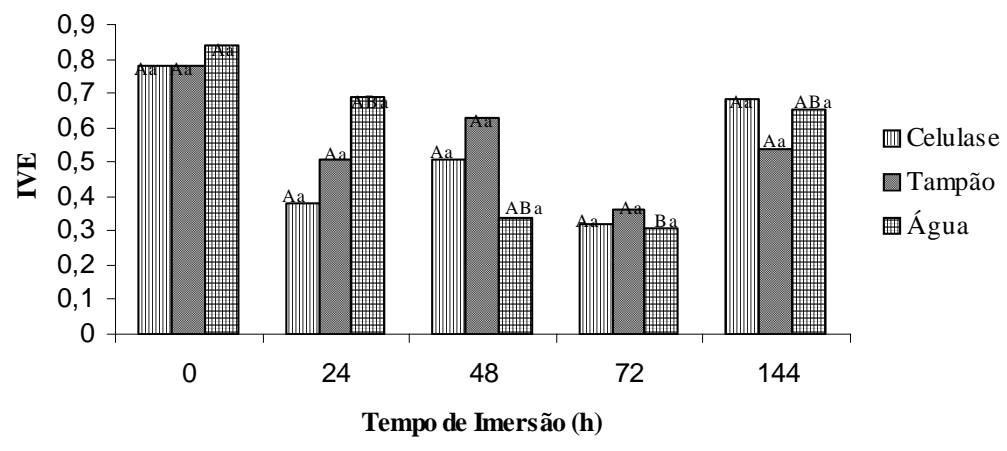

FIGURA 3 - Índice de Velocidade de Emergência (IVE) de sementes de cafeeiro com pergaminho após a imersão por diferentes períodos em solução de celulase, tampão citrato de potássio e água. ${ }^{\mathrm{z}}$ Médias seguidas pela mesma letra maiúscula entre tempos de imersão dentro de cada substância e minúsculas entre substâncias dentro de cada tempo de imersão não diferem entre si pelo teste de Tukey ao nível de 5\% de probabilidade. 


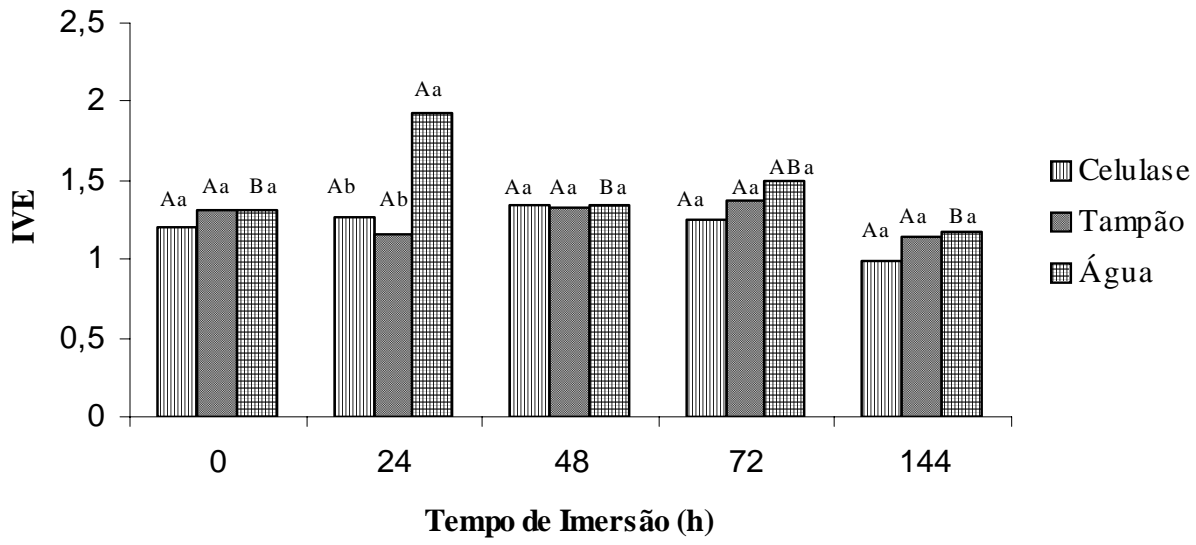

FIGURA 4 - Índice de Velocidade de Emergência (IVE) de sementes de cafeeiro sem pergaminho após a imersão por diferentes períodos em solução de celulase, tampão citrato de potássio e água. ${ }^{\mathrm{z}}$ Médias seguidas pela mesma letra maiúscula entre tempos de imersão dentro de cada substância e minúsculas entre substâncias dentro de cada tempo de imersão não diferem entre si pelo teste de Tukey ao nível de 5\% de probabilidade.

TABELA 3 - Porcentagem de emergência de plântulas de cafeeiro após imersão por diferentes períodos em solução de celulase (1,6 g.L $\left.{ }^{-1}\right)$, tampão citrato de potássio 0,05 M e da água.

\begin{tabular}{cccccccc}
\hline \multirow{2}{*}{ TS $^{\mathrm{X}}$} & \multirow{7}{c}{ Solução } & \multicolumn{7}{c}{ Tempo de imersão (h) } \\
\cline { 3 - 7 } & & 0 & 24 & 48 & 72 & 144 & Média \\
\hline \multirow{4}{*}{$\mathrm{CE}$} & Celulase & $90 \mathrm{Aa}^{\mathrm{Y}}$ & $31,5 \mathrm{Dc}$ & $65 \mathrm{Bb}$ & $46 \mathrm{Ca}$ & $90 \mathrm{Aa}$ & $64,5 \mathrm{~b}$ \\
& Tampão & $88 \mathrm{Aa}$ & $64 \mathrm{Cb}$ & $91 \mathrm{Aa}$ & $50 \mathrm{Da}$ & $80,25 \mathrm{Bb}$ & $74,65 \mathrm{a}$ \\
& Água & $73 \mathrm{Cb}$ & $88 \mathrm{Aa}$ & $47 \mathrm{Dc}$ & $41 \mathrm{~Eb}$ & $80 \mathrm{Bb}$ & $65,8 \mathrm{~b}$ \\
& Média & $83,66 \mathrm{~A}(\mathrm{~b})$ & $61,16 \mathrm{C}(\mathrm{b})$ & $67,66 \mathrm{~B}(\mathrm{~b})$ & $45,66 \mathrm{D}(\mathrm{b})$ & $83,41 \mathrm{~A}(\mathrm{~b})$ & $68,31(\mathrm{~b})$ \\
& Celulase & $98 \mathrm{Aab}$ & $98 \mathrm{Aa}$ & $98 \mathrm{Aa}$ & $98 \mathrm{Aa}$ & $82 \mathrm{Bb}$ & $94,8 \mathrm{~b}$ \\
$\mathrm{SE}$ & Tampão & $94 \mathrm{Ab}$ & $97 \mathrm{Aa}$ & $97 \mathrm{Aa}$ & $98 \mathrm{Aa}$ & $94 \mathrm{Aa}$ & $96,0 \mathrm{~b}$ \\
& Água & $100 \mathrm{Aa}$ & $100 \mathrm{Aa}$ & $98 \mathrm{ABa}$ & $100 \mathrm{Aa}$ & $94 \mathrm{Ba}$ & $98,4 \mathrm{a}$ \\
& Média & $97,33 \mathrm{~A}(\mathrm{a})$ & $98,33 \mathrm{~A}(\mathrm{a})$ & $97,66 \mathrm{~A}(\mathrm{a})$ & $98,66 \mathrm{~A}(\mathrm{a})$ & $90,0 \mathrm{~B}(\mathrm{a})$ & $96,4(\mathrm{a})$ \\
\hline
\end{tabular}

${ }^{\mathrm{X}}$ Tipo de semente (CE, com endocarpo; SE, sem endocarpo) ${ }^{\mathrm{Y}}$ Médias seguidas pela mesma letra maiúscula na horizontal e minúscula na vertical dentro de cada tipo de semente, não diferem entre si pelo teste de Tukey ao nível de $5 \%$ de probabilidade. Letras entre parênteses deverão ser comparadas apenas entre tipos de sementes dentro de cada tempo de imersão.

\section{CONCLUSÕES}

Diante dos resultados, conclui-se que a hidrólise do pergaminho das sementes do cafeeiro in vitro é diretamente proporcional à concentração da solução de celulase; a hidrólise do pergaminho das sementes do cafeeiro cresce linearmente em função do tempo de exposição à solução de celulase; sementes sem pergaminho apresentam maiores IVG, IVE, germinação e emergência que as sementes com pergaminho; a celulase na concentração de 1,6 g.L.-1 não proporcionou aumento da velocidade de germinação das sementes.

\section{AGRADECIMENTOS}

Ao consórcio Brasileiro de Pesquisas e Desenvolvimento do café (CBP\&D- Embrapa/Café) pelo patrocínio parcial desta pesquisa e à FAPEMIG pela bolsa de mestrado da primeira autora. 


\section{REFERÊNCIAS BIBLIOGRÁFICAS}

ANUÁRIO estatístico do café. Rio de Janeiro: Coffe Business, 1997.

BRASIL. Ministério da Agricultura. Regras para análise de sementes. Brasília, DF: DNPV/DISEM, 1992. 365 p.

CAMARGO, R. de. Condicionamento fisiológico de sementes de cafeeiro (Coffea arabica L.). 1998. $108 \mathrm{f}$. Dissertação (Mestrado em Fitotecnia) - Universidade Federal de Lavras, Lavras, 1998.

FRANÇA, C. M. Apontamentos de fisiologia do cafeeiro. Campinas: Secretaria da Agricultura do Estado de São Paulo, 1970. 55 p.

GUIMARÃES, R. J. Análise do crescimento e da quantificação de nutrientes em mudas de cafeeiro (Coffea arabica L.) durante seus estádios de desenvolvimento em substrato padrão. 1995. 113 f. Dissertação (Mestrado em Fitotecnia) - Escola Superior de Agricultura de Lavras, Lavras, 1995.

GUIMARÃES, R. M. Tolerância à dessecação e condicionamento fisiológico em sementes de cafeeiro (Coffea arabica L.). 2000. 180 p. Tese (Doutorado em Fitotecnia) - Universidade Federal de Lavras, Lavras.
HOWARD, G. T.; ELLIOTTI, L. P. Effects of cellulolytic ruminal bacteria and of cell extracts on germination of Euonymus americanus L. seeds. Applied and Environmental Microbiology, Washington, v. 54, n. 1, p. 218-224, 1988.

LIMA, W. A. A. Condicionamento fisiológico, germinação e vigor de sementes de café (Coffea arabica L.). 1999. 69 f. Dissertação (Mestrado em Fitotecnia) - Universidade Federal de Viçosa, Viçosa, 1999.

MAGUIRRE, J. D. Speed of germination aid in selection and evaluation for seedling and vigour. Crop Science, Madison, v. 2, n. 2, p. 176-177, Mar./Apr. 1962.

MARCONDES, D. M. S. S. V.; SILVA, D. M.; VITTI, L. S. S.; SILVA, J. C. Celulase do extrato de rúmen bovino. Energia Nuclear e Agricultura, Piracicaba, v. 5, n. 2, p. 145-160, 1983.

NECHET, K. de L. Caracterização biológica e isoenzimática de isolados de Colletotrichum sp em cafeeiro (Coffea arabica L.). 1999.73 p. Dissertação (Mestrado em Fitopatologia) Universidade Federal de Lavras, Lavras, 1999.

RENA, A. B.; MAESTRI, M. Fisiologia do cafeeiro. In: SIMPÓSIO SOBRE FATORES QUE AFETAM A PRODUTIVIDADE DO CAFEEIRO, 1986, Poços de Caldas, MG. Anais... Piracicaba: POTAFÓS, 1986. p. 13-85. 